\title{
INTERESSES E AÇÕES DE JOÃO FERNANDES VIEIRA E ANDRÉ VIDAL DE NEGREIROS CONTRA O ESTADO DO CONGO: TRÁFICO DE ESCRAVIZADOS E OUTROS NEGÓCIOS DA ÁFRICA CENTRO OCIDENTAL PARA PERNAMBUCO (1658-1666)
}

INTERESTS AND ACTIONS OF JOÃO FERNANDES VIEIRA AND ANDRÉ VIDAL DE NEGREIROS AGAINST THE STATE OF CONGO: SLAVE TRADE AND OTHER BUSINESSES FROM WEST CENTRAL AFRICA TO PERNAMBUCO (1658-1666)

Prof. Dr. Leandro Nascimento de Souza (UFRPE)*

\begin{abstract}
Resumo
Esse artigo se propõe a analisar as ações contra o Estado do Congo, realizadas por João Fernandes Vieira e André Vidal de Negreiros enquanto governadores de Angola, no período de 1658 a 1666, tendo como focos principais de atenção as relações de poder, as ações militares e o tráfico de escravizados para Pernambuco. Demonstra-se, ao longo desse trabalho, que os poderes adquiridos, em função do prestígio acumulado pelas ações em Pernambuco, permitiram que eles pudessem agir de acordo com os seus interesses, desconsiderando vários aspectos do regimento para Angola, num jogo político que envolveu eclesiásticos, soberanos regionais e locais, a aristocracia lusitana, e a própria Coroa portuguesa com o Conselho Ultramarino. Para tanto, foram feitas análises de fontes arquivísticas, como a documentação do Arquivo Histórico Ultramarino e da coleção Monumenta Missionária Africana, além de cronistas da época.
\end{abstract}

Palavras chaves: Ações militares; Estado do Congo; tráfico de escravizados.

\begin{abstract}
This article proposes to analyze the actions against the State of Congo, carried out by João Fernandes Vieira and André Vidal de Negreiros as governors of Angola, in the period from 1658 to 1666, having as main focus of attention the power relations, the military actions and the slave trade to Pernambuco. It is demonstrated, throughout this work, that the powers acquired, due to the prestige accumulated by the actions in Pernambuco, allowed them to act according to their interests, disregarding various aspects of the regiment for Angola, in a political game that involved ecclesiastics, regional and local sovereigns, the Portuguese aristocracy, and the Portuguese crown itself with the Overseas Council. To this end, analyzes were made from archival sources, such as documentation from the Overseas Historical Archive and the Monumenta Missionária Africana collection, in addition to chroniclers of the time.
\end{abstract}

Keywords: Military actions; Congo State; slave trade.

\footnotetext{
* Possui doutorado em História Social pela Universidade Federal Fluminense, atualmente é professor de História da África e da Cultura Afro-brasileira do EAD-UFRPE
} 


\title{
Introdução
}

\begin{abstract}
Ai, ó rei do Congo, que castigo, que castigo ameaça a tua coroa. Chegará sem demorar muito tempo. O filho será castigado pelo pecado do pai. Perderá ele o reino e a vida em batalha ${ }^{1}$
\end{abstract}

Os problemas entre Portugal e o Estado do Congo vinham de longa data, mas a situação se agravou em 1641, quando Garcia II, Kimpaco, destronou seu irmão e assumiu a soberania do Congo. No mesmo ano em que os holandeses chegaram a Luanda, Garcia II prestou auxílio aos flamengos com "tropas negras", para combater os colonos lusitanos e seus aliados, que se refugiaram em Massangano. Esse mesmo soberano, em maio de 1643, enviou embaixadores seus para negociar o comércio escravista diretamente com Maurício de Nassau, no Recife. Durante toda a ocupação holandesa em Angola, Garcia II e Nzinga, influenciaram a África Centro Ocidental a se levantar contra os invasores portugueses, além do que o Congo recuperou terras que os portugueses tinham invadido com a colonização em Angola, absorvendo grande número de cativos. A política externa do Estado do Congo no período em questão foi de romper com os intermediários nas questões econômicas, políticas e religiosas, diminuindo ainda mais as influências portuguesas na região ${ }^{2}$.

Com a retomada de Luanda em 1648, Salvador Correia de Sá enviou tropas sob o comando de Bartolomeu de Vasconcelos da Cunha em direção ao Congo, degolando os sobas inimigos no caminho. Frente a essa ameaça, Garcia II enviou embaixadores para um tratado de paz em Luanda. O governador geral tentou obrigar o Congo a devolver terras anexadas no período dos holandeses e restituir todos os escravos fugidos e capturados ${ }^{3}$. O tratado de paz foi criado, mas houve muita discórdia entre as partes, e Garcia II foi acusado pelos governadores gerais de Angola de não o cumprir ${ }^{4}$. A grande questão foi que Garcia II não esteve isolado, teve aliados no

\footnotetext{
${ }^{1}$ Ameaça profética do Padre Jesuíta João Paiva ao rei do Congo Garcia II em 1641, segundo ele, pelas suas atitudes contra o Padroado Régio. MONTECÚCCOLO, Pe. João António Cavazzi de. Descrição histórica dos três reinos do Congo, Matamba e Angola. Volume 2. Lisboa: Junta de Investigações do Ultramar, 1965, p. 13.

${ }^{2}$ ALENCASTRO, Luiz Felipe de. O trato dos viventes: Formação do Brasil no Atlântico Sul. São Paulo: Companhia das letras, 2000, p. 284-285.

${ }^{3}$ Ver capitulações do tratado em: Consulta do Conselho Ultramarino em 27 de julho de 1651. In: BRÁSIO, Padre Antonio. Monumenta Missionária Africana. Série 1, Volume 11. Lisboa: Agência Geral do Ultramar, 1971, p. 61-65.

${ }^{4}$ Em 1653, o governador de Angola Rodrigo de Miranda Henriques, queixa-se da falta de cumprimento do tratado de paz pelo soberano do Congo e sobas vassalos. O Rei de Portugal solicitou que se faça valer o tratado, mas com muita cautela, evitando conflitos. Arquivo Histórico Ultramarino-Angola. 31/03/1653. CU-01, CX-5, D-530. Em 1656 e 1657, tanto o governador de Angola Luis Martins de Sousa, quanto a Câmara de Luanda, queixaram-se do não cumprimento do tratado por parte do Estado do Congo, foi feito uma junta, mas não tiveram apoio de alguns religiosos. Consulta do Conselho Ultramarino. In: CADORNEGA, Antonio de Oliveira de. História Geral das Guerras Angolanas. V-2. Lisboa: Agênciageral do Ultramar, 1940, p. 509-510.
} 
clero conguês que negociou apoio nesses assuntos diretamente com Roma e ainda com Madri, além dos outros Estados europeus, com quem teve negócios através do porto de Pinda. Essas questões fizeram com que uma guerra direta contra ele só fosse possível com uma boa justificativa por parte dos portugueses 5 .

\section{As tentativas de João Fernandes Vieira}

Desde que chegou a Angola, Vieira tratou de justificar a guerra contra o Congo, tentou criar uma rede de influências para ter uma base aliada que lhe desse mais credibilidade perante a Coroa. Nas cartas enviadas a Coroa portuguesa, ele fez questão de mostrar que sempre consultou a Câmara de Luanda nas decisões e que sempre teve unanimidade nos votos. Talvez a guerra contra o Congo tenha sido um interesse em comum entre os moradores de Luanda, pois, no governo de Luís Martins de Sousa Chichorro a Câmara de Luanda teve a mesma atitude de apoiar a guerra ${ }^{6}$. Na carta, ele acusou Garcia II de ter cometido várias atrocidades contra os aliados da Coroa portuguesa, mais do que todos os outros inimigos juntos, tais como saques a fazendas, vilas e aos vassalos da Coroa portuguesa. Levantou a questão de que o catolicismo praticado no Congo era superficial, pois tinha suas práticas "pagãs", e o próprio soberano não utilizava seu nome cristão ${ }^{7}$. Vieira ainda informou que Garcia II havia entrado em contato com Nzinga recentemente para uma possível aliança contra os portugueses ${ }^{8}$. Vieira acusou também Garcia II de ter enganado a Coroa, porque não tinha cumprido o acordo com Salvador Correia de Sá, usando falsas promessas com os outros governadores, querendo fazer o mesmo com ele próprio. No documento, João Fernandes relatou que, no início do seu governo, tinha dado um ultimato ao soberano do Congo, com prazo de oito meses para cumprir o acordo de Salvador de Sá, senão haveria a guerra. Próximo do prazo chegar ao fim, o soberano do Congo enviou, talvez para ganhar tempo, 200 escravos formados de velhos e crianças, o que para Vieira foi uma grande frustração. Três dias depois da declaração, Vieira teve o apoio unânime dos conselheiros de Luanda, eles afirmaram que o exército e os aliados estavam prontos para a guerra. Fica clara nas afirmações de João

\footnotetext{
${ }^{5}$ Em 6 de outubro de 1660, o secretário da Propaganda Fide enviou uma carta ao Cardeal Vírginio Orsini, solicitando que se peça ao governador geral de Angola que compreenda mais o soberano do Congo, evitando conflitos e cedendo a questões justas. BRÁSIO, Padre Antonio. Monumenta Missionária Africana. Série 1, Volume 12. Lisboa: Academia Portuguesa da História, 1981, p. 309.

${ }^{6}$ Auto sobre a declaração de guerra a D. Garcia II, Rei do Congo, datada de 9 de junho de 1657. BRÁSIO, Padre Antonio. Monumenta Missionária Africana. 1981. p. 124-125. Ver também carta do governador geral de Angola Luis Martins de Sousa ao Rei, de 15 de junho de 1657. Arquivo Histórico Ultramarino-Angola. 15/06/1657. CU-01, CX-6, D-703.

${ }^{7}$ Informações que Vieira adquiriu através de padres capuchinhos que tinham vindo de São Salvador, capital do Congo. Posteriormente essa foi uma das justificativas de André Vidal de Negreiros para ter apoio no conflito de 1665. Esse caráter pagão do cristianismo do Estado do Congo foi um assunto que preocupou Roma, o Papa Alexandre VII, enviou uma carta a Garcia II, datada de 5 de outubro de 1660, que incitou o soberano de "exterminar as práticas pagãs viciosas da população". BRÁSIO, Padre Antonio. Monumenta Missionária Africana. 1981. p. 301-302.

${ }^{8}$ Desde 1656, Nzinga tinha sido neutralizada como ameaça aos portugueses, por conta do acordo diplomático com o governador Luis de Sousa, e da sua nova conversão ao cristianismo.
} 
Fernandes, a tentativa de inferiorizar o Estado do Congo perante a Coroa lusitana, usando termos que diminuíssem um soberano que era um agente importante da política regional, até mesmo global naquele momento 9 .

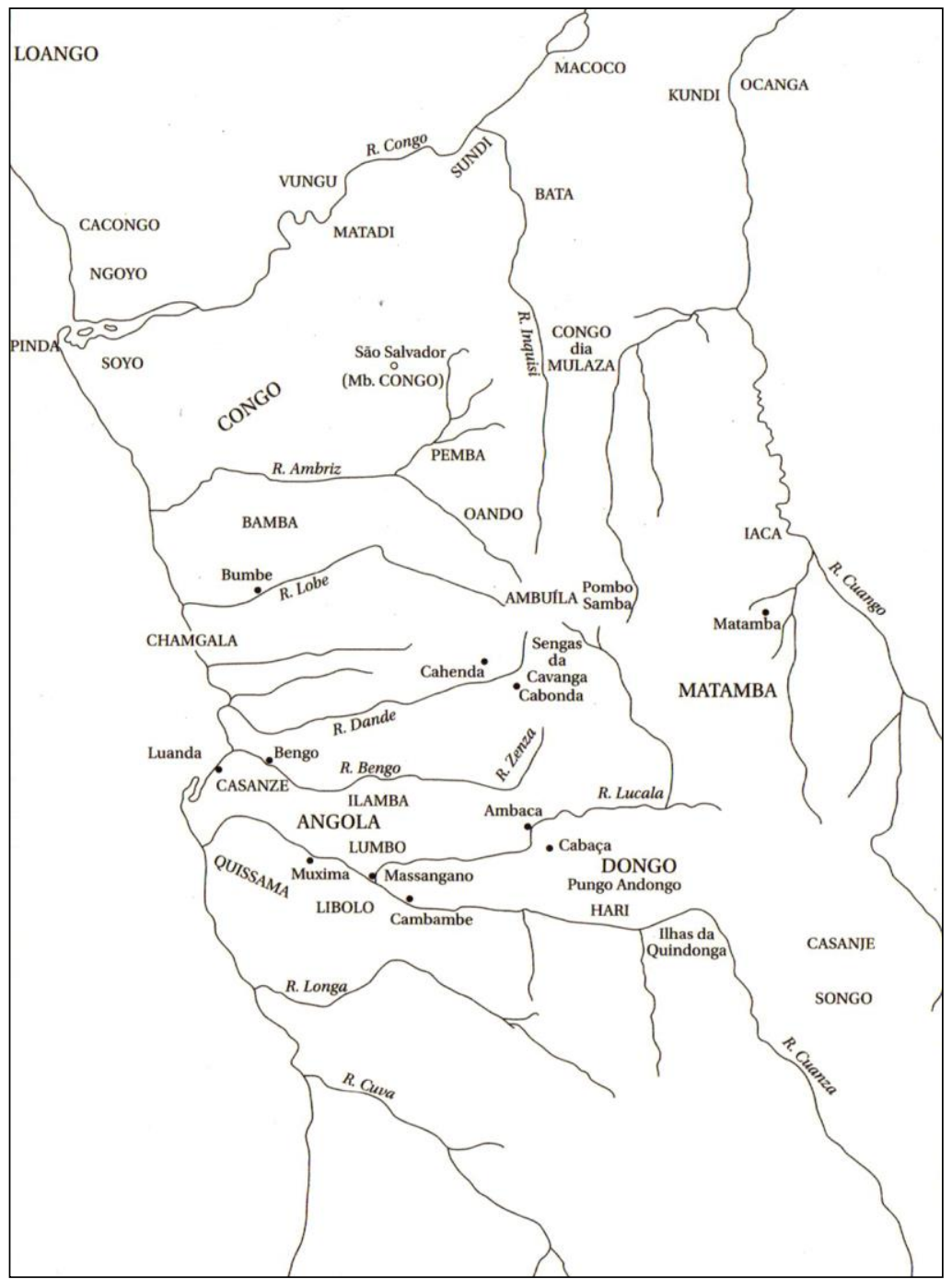

África Centro Ocidental, século XVII ${ }^{10}$

Sem a autorização para a guerra, Vieira escreveu mais uma vez ao Rei D. Afonso VI, solicitando a autorização com novas justificativas. Ele relatou que não tinha como negociar uma paz, pois já tinha oferecido amizade ao soberano do Congo em troca do cumprimento do acordo de Salvador de Sá, e que Garcia II continuava acolhendo cativos fugidos em suas terras e que a única alternativa para recuperar o prestígio era fazer guerra ao Congo. Vieira enfatizou que, se o

\footnotetext{
${ }^{9}$ Para compreender melhor a importância e as relações políticas do Congo com seus vizinhos no período analisado ver: VANSINA, J. O reino do Congo e seus vizinhos. In: OGOT, Bethwell Allan (org.). História Geral da África V. Brasília: UNESCO. 2010.

${ }^{10}$ SOUZA, Marina de Mello e. Além do Visível: poder, catolicismo e comércio no Congo e em Angola (séculos XVI e XVII). São Paulo: Editora da USP, 2018, p. 24.
} 
Congo fosse derrotado, os outros sobados perderiam sua força, possibilitando submissões ou novas alianças que poderiam favorecer os interesses da Coroa lusitana. Nessa carta, Vieira teve o apoio de uma junta religiosa, formada por franciscanos e capuchinhos, apoiando a guerra e relatando o caráter pagão do cristianismo no Congo e de como isso poderia influenciar negativamente as práticas cristãs na África Centro Ocidental ${ }^{11}$.

Três dias depois, Vieira enviou outra carta ao Rei de Portugal, enfatizando seus feitos como governador geral e capitão-general, relatou sobre a captura de embarcações holandesas e inglesas na Costa de Angola, como também o sucesso momentâneo na guerra dos sertões contra os sobas de Ambaca, Libolo, Benguela e Quissama. Fez relatos também sobre suas obras de fortificação de Luanda com custos baixos para a Coroa. Ficam evidentes as tentativas e várias formas que Vieira utilizou para justificar a guerra contra o Congo, dessa vez tentando mostrar a sua competência como gestor e militar, buscando passar mais credibilidade para a Coroa. Quatro meses depois, João Fernandes escreveu outra carta ao Rei D. Afonso VI, na qual relatou a vontade do povo de Luanda em fazer guerra ao Congo, desde o tempo de Luis de Sousa Chichorro, e que continuam aguardando a autorização da Coroa ${ }^{12}$.

Na documentação, fica evidenciada a determinação de Vieira em combater o Estado do Congo, o que só viria a acontecer em 1665 com o seu sucessor André Vidal de Negreiros. O receio de a Coroa portuguesa em atender às reivindicações de guerra estava relacionado, também, com o contexto europeu, pois Portugal ainda estava em conflito com a Espanha e a Holanda, e uma guerra aberta ao Congo poderia ter tido um custo muito alto, além da possibilidade da derrota e colocar em risco os territórios que tinham sua influência. Mas a insistência de Vieira diminuiu pelo fato de que, ou no fim de 1659 ou no início de 1660, o soberano do Congo cumpriu parte do acordo de Salvador de Sá, entregando parte dos escravos fugidos que estavam em suas terras, João Fernandes mandou entregar os escravos aos seus devidos donos ${ }^{13}$. Embora ele não tenha conseguido a tão desejada guerra contra o Congo, conseguiu que parte do acordo com Garcia II tenha sido cumprido, algo que nenhum dos seus antecessores conseguira. Provavelmente as campanhas aos sobas inimigos dos lusitanos impactaram os congueses.

\section{Moedas de troca na África Centro Ocidental: tentativas de estabelecer o cobre}

Vários tipos de produtos foram utilizados como moeda de troca ao longo da invasão europeia na região de Angola, dentre os principais temos o nzimbu ou cauri, pequena concha ou

\footnotetext{
${ }^{11} \mathrm{Em} 7$ de maio de 1659. Arquivo Histórico Ultramarino-Angola. 07/05/1659. CU-01, CX-6, D-729.

${ }^{12} \mathrm{Em} 10$ de maio de 1659 e em 24 de setembro de 1659. Arquivo Histórico Ultramarino-Angola. CU-01, CX-6, D-732,740.

${ }^{13}$ CADORNEGA, Antonio de Oliveira de. História Geral das Guerras Angolanas. p. 181.
} 
búzio, extraído das praias da Ilha de Luanda ${ }^{14}$. No fim do século XVI, comerciantes do Atlântico inundaram a África Centro Ocidental com os nzimbus. Muitas dessas moedas de troca começaram a ser trazidas de regiões fora da África Atlântica, desvalorizando a principal moeda do Congo, comprometendo o controle econômico desse Estado ${ }^{15}$. No início do século XVII, o marfim vindo de Benguela era a principal fonte de receita do comércio com o exterior, juntamente com os escravizados e o sal, proveniente das minas ou salinas de Quissama, onde era moldado em pedras e barras. Mas foi o libongo, pequeno pedaço de tecido de várias dimensões e qualidades, feito à base de fibras da palmeira-bordão, que ganhou o mercado em Angola ao longo do século XVII ${ }^{16}$. Os panos libongos causaram uma grande preocupação entre os administradores portugueses, pois se tornou muito desvalorizado, o que dificultava o controle mercantil. Os portugueses insistiram, ao longo da segunda metade dos seiscentos, em substituir esses panos pela moeda de cobre, desejando que o metal se tornasse uma referência nas transações comerciais e pagamentos dos soldados, sendo o material mais usado para fabricação de utensílios de uso diário como facas, enxadas, flechas, punhais, copos, manilhas e colares.

As primeiras reclamações lusitanas a respeito surgiram em 1645, enquanto os holandeses ainda ocupavam Luanda, e quando Francisco de Souto-Maior se estabeleceu em Quicombo, na enseada do rio Longa, para reforçar a resistência lusitana. Ele informou que a região possuía muitas minas de cobre para cunhagem de moedas, o que facilitaria o pagamento dos soldados, como também o comércio em Angola, que estava dominado pelos libongos ${ }^{17}$.

No governo de Salvador Correia de Sá, houve uma ação em conjunto para acabar com os panos enquanto moeda. A Câmara de Luanda apresentou-lhe um requerimento propondo que se criasse moeda para o sustento da infantaria. A nova moeda devia ser de cobre, com o peso de

\footnotetext{
${ }^{14}$ Os nzimbus foram por muito tempo a principal moeda de troca no Estado do Congo, o que gerou uma disputa pelo domínio da Ilha de Luanda entre portugueses e conguêses. No início do século XVII, os portugueses fizeram uso de búzios vindos das costas de Benguela e do Brasil para as transações comerciais na região, ocasionando uma desvalorização do produto na década de 1620. HEINTZE, Beatrix. Angola nos séculos XVI e XVII: estudos sobre fontes, métodos e história. Luanda: Ed.Kilombelombe, 2007, p. 109111.

${ }^{15}$ GREEN, Toby. A fistful of shells: West Africa from the rise of the slave trade to the age of Revolution. Chicago: The University of Chicago Press, 2019, p. 189.

${ }^{16}$ Vindo de Loango e chamado pelos locais de mukuta, passou a ser usado pelos colonos portugueses com a nomenclatura macuta, cujo nome foi atrelado as primeiras moedas de cobre no fim do século XVII em Angola. BRÁSIO, Padre Antonio. Monumenta Missionária Africana. Série 1, Volume 9. Lisboa: Agência Geral do Ultramar, 1952, p. 376. Sobre os valores referente aos produtos e suas trocas mercantis em Angola no século XVII ver: PARREIRA, Adriano. Economia e sociedade em Angola na época da Rainha Jinga (século XVII). Lisboa: Editorial Estampa, 1989, p. 86-89.

${ }^{17} \mathrm{Em} 1546$, houve relatos de portugueses no rio Longa, resgatando cobre na região de Benguela. No período do governo de Paulo Dias de Novaes, o mesmo enviou Lopes Peixoto em 1586 para invadir a região, com o intuito de extrair o cobre existente, depois de construída a fortaleza, um grupo em torno de 70 lusitanos, foram mortos pelos povos locais, por terem invadido seus territórios. BRÁSIO, Padre Antonio. Monumenta Missionária Africana. 1952, p. 375.
} 
duas oitavas e dois terços, chamada de "meio pano" e com o valor de 25 réis, a outra se chamaria "libongo", com o peso de uma oitava e um terço, valendo 12 réis e meio. Esse auto, do início de 1649, exprimia a opinião da Câmara, oficiais de justiça, clero, militares, grandes comerciantes, muitos desses representantes assinaram o documento, inclusive o governador geral ${ }^{18}$. Em agosto de 1649, o Conselho Ultramarino deu parecer desfavorável, em virtude de que poderia prejudicar o comércio na região do Libolo, onde havia alguns agentes comerciais lusitanos tentando resgatar a influência mercantil de Portugal, a qual estava sendo ameaçada pelos outros reinos europeus. $\mathrm{O}$ parecer também argumentava que a extinção dos panos como moeda de troca naquele momento poderia dificultar a reconciliação com o Estado do Congo, que também se utilizava deles da mesma forma.

D. João IV concordou com o Conselho e vetou o auto, informando ainda que os valores que tinham sidos estipulados poderiam concorrer com as moedas de Castela, abrindo espaço para esse tipo de troca mercantil com outras nações europeias ${ }^{19}$. Foi um momento delicado para a Coroa, pois, no início do governo, Salvador Correia de Sá atacou alguns sobas aliados do Congo na região do Dande e ainda estava organizando uma coluna punitiva ao Congo, pelas ações no período da ocupação holandesa. Garcia II, o Kinpaco, enviou embaixadores para negociar um tratado de paz com Angola. Em março de 1649, o já citado tratado foi enviado para a aprovação de D. João IV, o qual vetou alguns itens por achar que seria uma ofensa ao soberano Garcia II. O Rei lusitano fez questão de ratificar que o soberano do Congo não era seu vassalo, mas sim um "irmão de armas". A principal capitulação que foi eliminada pela Coroa na emissão do novo tratado, em setembro de 1651, foi a exigência de Salvador Correia de Sá estipulando que toda mina de ouro, prata ou cobre potencialmente existentes deveriam pertencer à Coroa de Portugal. O Rei tinha sido aconselhado pelo Conselho Ultramarino, que tinha muito mais a ganhar concedendo uma paz tranquila. Portanto, autorizar a questão das moedas de cobre, nesse momento, poderia enfraquecer essas relações, sobretudo comerciais ${ }^{20}$. Na prática, tanto o tratado de 1649 , quanto o de 1651 não foram cumpridos de ambos os lados.

André Vidal de Negreiros e o Mani Mulanza: religiosos, conflitos e as minas de ouro e de cobre do Congo

\footnotetext{
${ }^{18}$ Auto sobre a cunhagem da moeda, datado em 31 de janeiro de 1649. Arquivo Histórico UltramarinoAngola. CU-01, CX-4, D-447.

${ }^{19}$ Consulta do Conselho Ultramarino em 18 de agosto de 1649. Carta régia ao governador de Angola, em 18 de fevereiro de 1650. BRÁSIO, Padre Antonio. Monumenta Missionária Africana. 1965, p. 391-394, 476-477.

${ }^{20}$ BOXER, Charles. Salvador de Sá: e a luta pelo Brasil e Angola, 1602-1686. São Paulo: Companhia editora Nacional, 1973, p. 289-290. No tratado de 1649, uma das capitulações, foi que o Estado do Congo tinha que pagar um tributo anual em grande quantidade de panos comerciais.
} 
Quatorze anos depois do veto em cunhar moedas de cobre, o Conselho Ultramarino mudou sua análise. O governador André Vidal expôs novamente os problemas relacionados aos panos como moeda de troca na praça de Luanda, comprometendo não só o pagamento dos soldados, mas também as várias atividades econômicas na região. Ele sugeriu, então, que fosse aplicado às cunhagens das moedas, pois afirmara que havia muito desse minério na região e ainda relatou o interesse da Câmara e do povo de Luanda sobre esse assunto, e que os contratadores dos panos poderiam se adaptar a novas atividades mercantis. O Conselho Ultramarino deu parecer positivo ao governador, sugerindo ao Rei a aplicação da moeda, e relataram que os panos tinham caído muito de qualidade, perdendo cada vez mais o seu valor, o que gerava um prejuízo de dez mil cruzados por ano. A Coroa se pronunciou sobre o assunto, concordou com a substituição cambial e queria também implantar o processo no Brasil, mas, para tanto, exigiu informações mais detalhadas de como seria desenvolvida a questão, desde os locais de extração até sua fundição e de como se faria tudo sem prejudicar a fazenda real ${ }^{21}$.

Além disso, o Rei também mostrou preocupação com a composição dos contratadores e sugeriu que a câmara deveria ficar responsável por esse assunto. Era evidente o interesse da Coroa em ampliar a extração de cobre, principalmente para organizar a situação monetária em Angola e no Brasil. Em 1663, os juízes e oficiais da Câmara de Luanda solicitaram ao Rei a extinção dos libongos, afirmando que a aplicação das moedas de cobre seria viável, por haver muito desse material na região, como em Luango, Cambambe, Ambaca, Benguela e Libolo, e ainda estipularam as moedas em valores de 5 e 10 réis $^{22}$.

Apesar do interesse em comum, é bem provável que o governador tenha influenciado a Câmara no repasse dessas informações ao Rei, pois até então não se tinha conhecimento de que essas regiões citadas possuíam tanto potencial para extração de cobre, talvez uma tentativa de Negreiros de obter autorização para enviar gente sua para essas regiões em busca de transações escravistas. Sabe-se que, nos fins do mesmo ano, a Coroa solicitou ao governador geral de Angola que o mesmo averiguasse de forma imediata a existência de minas de cobre na costa de Angola e que seria muito bem recompensado, demonstrando assim que não havia atualmente a quantidade de cobre necessária para os interesses régios ${ }^{23}$. O cobre angolano também poderia ser um bom

\footnotetext{
${ }^{21} 1$ cruzado equivalia a 400 réis. 1 pano libongo equivalia a 12 réis. 1 escravizado equivalia a 22.000 réis, ou 165 florins. PARREIRA, Adriano. Economia e sociedade em Angola na época da Rainha Jinga (século $X V I I)$. p. 88-89. Nessa época o libongo estava sendo feito de peças de pano de cânhamo, quadrado, de três quartas de vara (a vara tinha $1,10 \mathrm{~m}$ ). Quatro libongos valiam cerca de um vintém. Carta do governador geral de Angola ao Rei, em 11 de fevereiro de 1662. Consulta do Conselho Ultramarino em 5 de outubro de 1663 e, carta régia ao governador geral de Angola, em 5 de novembro de 1664. BRÁSIO, Padre Antonio. Monumenta Missionária Africana. 1981, p. 456.-457, 506-507.

${ }^{22}$ Moradores de Angola sobre as medas de cobre. Arquivo Histórico Ultramarino-Angola. 1663. CU-01, CX-7, D-864.

${ }^{23}$ Carta régia ao governador geral de Angola, também assinada pelo Conde de Castelo Melhor, em 22 de dezembro de 1663. BRÁSIO, Padre Antonio. Monumenta Missionária Africana. 1981. p. 473.
} 
negócio para Negreiros, pois supriria as necessidades de materiais na fabricação do açúcar nos seus engenhos e nos demais do Brasil. Talvez ele vislumbrasse que poderia controlar parte desse mercado através de seus agentes comerciais em Luanda ${ }^{24}$. As evidências mostram que, em 1663, o governador aparece envolvido em várias atividades comerciais no porto de Luanda, desde ligação com contratadores de escravizados e sua arrematação para o Brasil à extração e comércio de Sal em Benguela ${ }^{25}$.

Com relação ao Estado do Congo e à Coroa portuguesa, havia uma grande insatisfação em Luanda por conta do tratado de paz não cumprido por Garcia II. A situação ficou ainda mais complicada quando Kinpaco faleceu em 1661, e seu segundo filho, D. Antonio, o Mani Mulanza, assumiu o Estado. Ele teve uma postura mais rígida com relação a Angola, denunciando ao Rei de Portugal que os governadores gerais de Angola estavam fazendo um desserviço à Coroa, porque não tratavam o Congo como um "irmão de armas", e ainda insistiam em querer submeter o Estado aos seus interesses próprios, através do uso do tratado de paz de 1649, que para ele não tinha valor, pois havia sido alterado pela Coroa portuguesa em $1651^{26}$. Mani Mulanza ainda acusou os governadores gerais de Angola de obstruírem sua comunicação com Portugal e os capuchinhos de estarem a serviço de Castela. O documento encerra-se com fortes críticas a João Fernandes e a André Vidal, sugerindo que governavam em função de seus próprios interesses em desacordo com o regimento e com o tratado de $1651^{27}$.

Os governadores e a Câmara de Luanda tentavam impor o tratado de 1649 elaborado por Salvador Correia de Sá, que, dentre várias questões, estipulavam as seguintes obrigações conguêsas: a devolução de todos os escravos fugidos para as suas terras; estabelecimento da liberdade de trânsito para os comerciantes lusitanos; intermediação da vassalagem dos Dembos com a Coroa lusitana; e cessão das minas de ouro para Portugal. Dentre os artigos retirados em 1651, o que mais incomodou os colonos em Angola foi a questão das minas. Apesar da guerra contra o Congo ter tido um conjunto de motivos, considera-se que a captura de escravizados pela guerra fosse o maior deles. Entretanto, nos documentos, uma das justificativas mais recorrentes

\footnotetext{
${ }^{24}$ Além de moedas, o cobre era utilizado em vários materiais bélicos, em várias ferramentas e utensílios do cotidiano, principalmente nos materiais usados nos engenhos de açúcar no Brasil, para esse período foi o minério mais utilizado nas colônias portuguesas do Atlântico, na segunda metade do século XVII. PARREIRA, Adriano. Economia e sociedade em Angola na época da Rainha Jinga (século XVII). p. 5658.

${ }^{25}$ Arquivo Histórico Ultramarino-Angola. 1663. CU-01, CX-7, D-824, 830, 831, 833, 842.

${ }^{26}$ A visão de mundo do Congo e de como os seus governantes lidavam com os Estados europeus estava relacionado as suas práticas culturais do passado, que consistia em trocar de parceiro comercial sempre que convinha, não ficavam presos a tratados escritos. GREEN, Toby. A fistful of shells: West Africa from the rise of the slave trade to the age of Revolution. p. 190, 193.

${ }^{27}$ Carta do Soberano do Congo contra os governadores de Angola. Arquivo Histórico Ultramarino-Angola. 12/09/1662. CU-01, CX-7, D-808.
} 
era a negativa em ceder acesso às supostas minas, seja pelos rumores existentes sobre a existência do ouro, ou pelas próprias minas de cobre que podiam interessar.

A relação entre André Vidal e D. Antonio ficou mais complicada com as já mencionadas campanhas militares promovidas pelo governador na região dos dembos. O Mani Mulanza solicitou a liberdade dos prisioneiros, alegando a injustiça da campanha. Houve a recusa, mas com a ressalva de que o caso poderia ser reanalisado caso o soberano conguês informasse a localização das minas e permitisse que a Coroa portuguesa as explorasse, ou até mesmo que concedesse a permissão para prospecções nas suas terras, conforme o tratado original realizado entre Salvador Correia de Sá e Garcia II.

D. Antonio discordou novamente. Ele continuava a alegar a ilegalidade das guerras na região dos dembos e, baseado no tratado de 1651, dizia não haver nenhuma obrigatoriedade de oferecer acesso às minas, que ele inclusive garantia não existirem. Aliás, afirmava também que quem descumpria o tratado eram os governadores gerais de Angola e não ele ${ }^{28}$. Nota-se que houve um fervor entre os agentes reais em Angola, na tentativa de submeter o Congo. Isso não seria tão fácil, pois o Mani Mulanza não se sentia na obrigação de cumprir as exigências, até mesmo por ser uma grande força política na macroregião, e com vários contatos externos, principalmente com Roma ${ }^{29}$.

Tendo em vista a dificuldade em convencer André Vidal, D. Antonio acionou seu corpo eclesiástico, o Cabido do Congo se envolveu na questão e escreveu ao governador geral, suplicando que o mesmo não fizesse guerra injusta ${ }^{30}$. Os religiosos reproduziram as mesmas argumentações anteriores e ainda ameaçaram escrever diretamente ao Papa e ao Rei de Portugal caso houvesse alguma investida de Angola contra os conguêses ${ }^{31}$. O Cabido era comandado pelos padres Simão de Medeiros, o vigário geral, e seu irmão Miguel de Castro. Naturais do Congo, faziam parte da realeza e, segundo os cronistas da época, foram aliados dos holandeses, articulando com sobados da região formas de expulsar os lusitanos. Juntos com Antonio de Couto, jesuíta em oposição aos capuchinhos, tentaram persuadir Negreiros a desistir do conflito na

\footnotetext{
${ }^{28}$ Estava se referindo a Ilha de Luanda, em posse dos portugueses desde a época de Salvador Correia de Sá, e da suserania dos dembos, em que João Fernandes e André Vidal realizaram campanhas militares. Carta do governador geral de Angola ao soberano do Congo D. Antonio I, em 15 de março de 1664. Carta de D. Antonio I soberano do Congo ao governador geral de Angola, em 13 de abril de 1664. Arquivo Histórico Ultramarino-Angola. 18/08/1665. CU-01, CX-8, D-1010.

${ }^{29}$ Para saber mais sobre os contratos de vassalagens entre europeus e africanos em Angola no século XVII ver: HEINTZE, Beatrix. Angola nos séculos XVI e XVII: estudos sobre fontes, métodos e história. p. 387436.

${ }^{30}$ Cabido: corporação de cônegos de alguma Sé. BLUTEAU, Pe. Raphael. Vocabulário português e latino. Coimbra: Collegio das Artes da Companhia de Jesus, 1712, p. 206.

${ }^{31}$ Carta datada de 13 de junho de 1665. Arquivo Histórico Ultramarino-Angola. CU-01, CX-8, D-1010.
} 
região $0^{32}$. O governador geral declarou que estava surpreso com as acusações e que não pretendia fazer guerra ao soberano D. Antonio, mas continuou insistindo com relação ao tratado de 1649, dessa vez informou que o próprio Mani Mulanza tinha-lhe informado que, apesar de não ter minas de ouro em seu Estado, ele possuía algumas minas de cobre.

D. Antonio emitiu em julho de 1665 um pregão de guerra contra Portugal, mandou que todos os senhores do seu Estado se preparassem para se juntarem ao soberano na defesa de suas terras, fazendas e liberdades contra a invasão portuguesa. Seis dias após o pregão, o Cabido do Congo voltou a escrever para o governador geral ressaltando mais uma vez que não existiam as minas de ouro, embora reconhecessem a existência das minas de cobre. Os Cônegos informaram também que, na época do soberano conguês D. Alvaro III, em 1622, foi disponibilizada para Portugal a possibilidade de prospecção na região. Naquele momento, a Coroa enviou mineiros para averiguarem a existência de ouro, mas não acharam nada que valesse a pena extrair, abandonando-as. Os Cônegos também alertaram que o Estado do Congo estava preparado para se defender de qualquer violência imposta por Negreiros.

A resposta do governador geral foi em agosto de 1665, informando conhecer a situação das minas no período filipino, e que, segundo ele, havia sido o próprio D. Alvaro III que expulsara os mineiros lusitanos da região do Embo $^{33}$. Ele informou na carta que essa situação de conflito poderia ter sido evitada, tanto por D. Antonio, se tivesse permitido as prospecções para averiguar as minas de ouro, ou explorar as de cobre já descobertas, quanto pelos Cônegos do Cabido do Congo que deveriam ter convencido o soberano conguês de não fugir das capitulações do tratado de 1649. Também informou sobre a experiência dele na expulsão dos holandeses na Capitania de Pernambuco e que estava preparado para atitudes hostis ${ }^{34}$.

A pressão entre os moradores de Luanda estava grande com relação à cunhagem das moedas e a exploração das minas de cobre nas terras do Congo. Em carta da Câmara de Luanda ao governador geral, os oficiais colocaram a responsabilidade da resolução do problema monetário para ele e exigiram que se fizesse valer o tratado de 1649 com o Congo. Informaram

\footnotetext{
${ }^{32}$ António de Couto, natural de Angola, fez-se jesuíta, estudou em Portugal, retornou para Angola com Salvador Correia de Sá em 1648, foi um dos maiores acusadores dos capuchinhos, e após a batalha de Ambuíla foi para Luanda, falecendo em 1666. Em 1662, Simão de Medeiros foi confessor de D. Antonio, tinha solicitado ao Rei de Castela que o nomeasse bispo do Congo, faleceu em 1667. Miguel de Castro assumiu como vigário geral com a morte do irmão, na guerra de sucessão no Congo após a batalha de Ambuíla, se colocou como possível ao trono, e faleceu em 1686. MONTECÚCCOLO, Pe. João António Cavazzi de. Descrição histórica dos três reinos do Congo, Matamba e Angola., p. 12, 381, 451, 463.

${ }^{33}$ Sobre os portugueses nas minas de cobre na região do Embo e de Bembe (Bamba) na década de 1620 ver: HEINTZE, Beatrix. Angola nos séculos XVI e XVII: estudos sobre fontes, métodos e história. p. 104. ${ }^{34}$ Pregão de guerra de D. Antonio contra os portugueses, 13 de julho de 1665. BRÁSIO, Padre Antonio. Monumenta Missionária Africana. 1981, p. 549-550. Cartas do Cabido do Congo e as respostas do governador de Angola: 19 e 25 de junho e 18 de agosto de 1665. Arquivo Histórico Ultramarino-Angola. CU, CX-08, D-1010.
} 
ainda que estavam com um déficit comercial alto e, desse modo, incapacitados de ajudar o governador geral com a guerra do Congo e no investimento nas minas, caso a situação não se resolvesse $\log 0^{35}$.

Nessa circunstância, André Vidal percebeu que não podia deixar passar a oportunidade de submeter o Estado do Congo naquele momento, pois poderia começar a perder apoio na Câmara de Luanda e de outros aliados que estavam se sentindo prejudicados financeiramente, portanto começou a articular formas para justificar o conflito. Convenientemente, em julho de 1665, o Conselho Ultramarino recebeu um dossiê a respeito do Cabido do Congo, acusando seus eclesiásticos de "paganismo" e de crime de "lesa majestade divina e humana". O autor foi o Deão de Angola, Manoel Fernandes Curado, o qual acusou principalmente os Cônegos Simão de Medeiros e Miguel de Castro de praticarem atividades espirituais fora do cristianismo, além de acusar os ditos Cônegos de incentivarem e parabenizarem os que lutaram contra os portugueses durante a invasão holandesa em Luanda. Curado ainda acusou os Cônegos de terem criado aliança com Castela, incentivando uma possível invasão em Luanda ${ }^{36}$.

As denúncias detalhadas foram enviadas pelo Conselho Ultramarino ao Rei, elas ainda reforçaram que o clero no Congo não tinha credibilidade, por se tratar de "mestiços congoleses carregados de suas crenças locais", e que o assunto deveria ser enviado diretamente para a Mesa de Consciência e Ordem, como também ao Tribunal de Santo Ofício.

Manoel Fernandes Curado, por sua vez, havia sido rejeitado pelo Cabido do Congo em 1661, mesmo tendo sido indicado pela Rainha D. Luisa de Gusmão ${ }^{37}$. Essa questão criou certo desconforto entre os corpos eclesiásticos, demonstrando a resistência dos Cônegos conguêses na entrada ou influência dos capuchinhos barbados no seu Estado. Outro fator a considerar é que o Deão de Angola poderia ter sido influenciado para construir essas justificativas para a guerra, a pedido do governador geral e da Câmara de Luanda.

Um dos pilares de sustentação da autonomia conguêsa foi justamente a ligação direta do seu corpo eclesiástico com Roma. Em maio de 1648, o soberano Garcia II realizou o Auto de Obediência ao Papa Inocêncio X, por intermédio dos missionários capuchinhos. No mesmo ano, o soberano foi informado de que, a pedido da Congregação da Propaganda Fide, seria presenteado

\footnotetext{
${ }^{35}$ Carta de 15 de abril de 1665. BRÁSIO, Padre Antonio. Monumenta Missionária Africana. 1981. p. 533534.

${ }^{36}$ Deão significa dignidade eclesiástica, na hierarquia do Cabido, o Deão está abaixo do Bispo ou Arcebispo. BLUTEAU, Pe. Raphael. Vocabulário português e latino. p. 361. A carta do Deão de Angola ao Rei de Portugal, foi em 29 de julho de 1665. Arquivo Histórico Ultramarino-Angola. CU, CX-08, D1004. As primeiras assinaturas que aparecem nas cartas enviadas pelo Cabido do Congo ao governador geral de Angola, foram dos cônegos Simão de Medeiros e Miguel de Castro.

${ }^{37}$ Consulta do Conselho Ultramarino, 12 de agosto de 1665. Carta da Rainha a Vidal de Negreiros, em 10 de julho de 1661. BRÁSIO, Padre Antonio. Monumenta Missionária Africana. 1981. p. 324, 559-562.
} 
com uma coroa real, benzida pelo próprio Papa, o soberano da Igreja havia recebido os embaixadores do Congo e parabenizado Garcia II pela defesa da fé católica ${ }^{38}$.

Segundo as crônicas dos próprios capuchinhos, foi na segunda missão ao Congo, em 1652, que iniciaram os atritos entre eles e o soberano da região, causado pela desconfiança de uma suposta aliança dos frades com o reino de Castela ${ }^{39}$. A situação se agravou com a morte de Garcia II, em 1661, e a crise na sucessão real, pois seu segundo filho, D. Antonio, assassinou o primogênito D. Afonso por suspeitar da aliança dele com os capuchinhos em um possível golpe contra seu pai. D. Antonio assumiu uma postura rígida contra os capuchinhos, tentando persuadir os portugueses de que havia uma suposta aliança entre Castela e a Propaganda Fide. Esse desentendimento fez com que os capuchinhos realizassem algumas denúncias sobre as práticas religiosas da região, colaborando, dessa maneira, com as justificativas portuguesas para uma guerra justa. Apesar das ameaças de Mani Mulanza e do seu corpo eclesiástico de denunciar as investidas lusitanas ao Papa, isso não foi realizado, pois as relações entre eles estavam fragilizadas, principalmente pelo desgaste do soberano com os capuchinhos da Propaganda Fide, Órgão que até então tinha ligação direta com Roma ${ }^{40}$.

Em setembro de 1665, o Conselho Ultramarino relatou ao Rei os detalhes sobre as hostilidades entre D. Antonio e André Vidal. A carta foi uma junta de várias justificativas para convencer a Coroa de que a guerra contra o Congo era justa, dentre elas, a afirmação da validade do tratado de 1649 sobre a questão das minas; a suposta aliança entre o Congo e a Espanha para uma invasão em Angola; e a necessidade de ajuda a sobas vassalos da Coroa, tais como o "Duque de Oando" que havia sido invadido por Matamba em $1663^{41}$. Essa última justificativa seria também importante, pois em 1665, com um novo soberano, Oando se levantou contra Matamba, dessa vez aliada do Congo, sendo derrotados mais uma vez, fugindo para as terras de Ambuíla.

\footnotetext{
${ }^{38}$ Auto de obediência ao Papa, 9 de maio de 1648. Carta de Inocêncio X ao soberano do Congo, 20 de maio de 1648. Carta do secretário da Propaganda Fide ao soberano Garcia II, sobre a coroa real, 3 de outubro de 1648. BRÁSIO, Padre Antonio. Monumenta Missionária Africana 1965. p. 129-135, 151-152, 250-251. A coroa real presenteada ao soberano Garcia II chegou ao Congo com os missionários capuchinhos em 1652, era de prata simples, mas com um belo trabalho artístico, enfeitada com várias joias preciosas. MONTECÚCCOLO, Pe. João António Cavazzi de. Descrição histórica dos três reinos do Congo, Matamba e Angola. p. 12.

${ }^{39}$ Questão observada em carta de Garcia II ao seu procurador, 8 de maio de 1656. BRÁSIO, Padre Antonio. Monumenta Missionária Africana. 1981, p. 22-23.

${ }^{40}$ MONTECÚCCOLO, Pe. João António Cavazzi de. Descrição histórica dos três reinos do Congo,

Matamba e Angola. p. 248.

${ }^{41}$ Consulta do Conselho Ultramarino, em 7 de setembro de 1665. BRÁSIO, Padre Antonio. Monumenta Missionária Africana. 1981. p. 568-573. Tanto o Conselho Ultramarino quanto a Coroa, a partir de 1663, desprezaram as alterações do tratado feitas em 1651, considerando a primeira versão de 1649 . Em julho de 1664, Negreiros já tinha colocado a possibilidade da aliança entre Congo e Castela. Arquivo Histórico Ultramarino-Angola. CU, CX-08, D-994. Sobre a junta de denúncias sobre o Congo ver Consulta do Conselho Ultramarino, 7 de setembro de 1665. BRÁSIO, Padre Antonio. Monumenta Missionária Africana. 1981. p. 568-573.
} 
Por sua vez, o senhorio de Ambuíla era liderado por uma soberana aliada dos portugueses, Dona Isabel Afonso, que, ao começar a sofrer ameaças do Estado do Congo, solicitou socorro ao governador geral de Angola ${ }^{42}$. A grande motivação para a ajuda lusitana foi a promessa do duque de Oando de que poderia revelar onde ficavam as minas de ouro, caso o governador geral enviasse o auxílio ${ }^{43}$. Mas, de fato, a existência das minas de ouro pouco importava para Negreiros, pois ele estava decidido a derrotar o Congo, justificado pelas minas de cobre e na resolução dos problemas dos panos libongos que dominavam e enfraquecia o comércio angolano, além de que, através da guerra, poderia aumentar o número de escravizados que poderiam ser enviados para o Brasil ${ }^{44}$.

\section{A batalha de Ambuíla e o tráfico de escravizados para Pernambuco}

André Vidal ordenou que o capitão-mor Luis Lopes de Siqueira fosse proteger o dembo de Ambuíla e o "duque" de Oando ${ }^{45}$. Foram articuladas tropas de várias praças de Angola, mas o grosso da campanha foi formado por gente dos sobas aliados. As fontes informam que houve aproximadamente 360 soldados portugueses entre os 6.000 cedidos pelos sobados para defender o território. D. Antonio mandou uma grande companhia ao encontro das tropas lusitanas na região do outeiro, que ficava entre o ducado de Oando e as terras da soberana Isabel em Ambuíla, justamente no local em que se especulava estarem localizadas as minas.

\footnotetext{
${ }^{42} \mathrm{O}$ auto de vassalagem de Dona Isabel regente de Ambuíla foi em 1 de janeiro de 1664 . O capitão Luis Lopes de Siqueira solicitou o auto por suspeitar de traição, o juramento foi feito por Isabel, e seu sobrinho (D. Alvaro Afonso, senhor de Bamba Ambuíla), e seus macotas. Nesse momento a soberana acusou o soberano do Congo e o Estado de Matamba de prejudicarem os interesses lusitanos nas rotas comerciais do interior. BRÁSIO, Padre Antonio. Monumenta Missionária Africana. 1981. p. 485-487.

${ }^{43}$ Negreiros já tinha informações sobre possíveis minas de cobre na região do Embo. Arquivo Histórico Ultramarino-Angola. 28?07/1665. CU, CX-08, D-1003. A justificativa de buscar minas na África Centro Ocidental para realizar outros objetivos foi utilizada em vários momentos pelos portugueses, como na expansão militar de Paulo Dias de Novaes, entre 1575 a 1588, e que apesar das minas de ouro não terem sido encontradas, conseguiu através da expansão outras conquistas mercantis. O mesmo aconteceu com relação às minas de prata de Cambambe, usadas pelos jesuítas para justificar a expansão militar do fim do século XVI e as missões da ordem nos sertões angolanos. CADORNEGA, Antonio de Oliveira de. História Geral das Guerras Angolanas. V-1, p. 11-45, 67-74.

${ }^{44}$ Desde 1656 que havia denúncias de cativos de Luanda e regiões próximas fugindo para o Estado do Congo. Os governadores gerais de Angola vindos do Brasil como João Fernandes e André Vidal comparavam a situação com Pernambuco, imaginando o Congo como um grande Palmares. BRÁSIO, Padre Antonio. Monumenta Missionária Africana. 1981. p. 42-43, 56.

${ }^{45}$ Luís Lopes de Siqueira, filho do capitão português de infantaria Domingos Lopes de Siqueira, e de mãe angolana, este oficial de infantaria distinguiu-se em Angola, no século XVII, como comandante militar do exército português, em quatro importantes confrontos armados contra os inimigos da Coroa: a batalha de Ambuíla, 1665, a batalha de Mpungu- a-Ndongo, 1671, a campanha do Libolo, 1679, e a campanha da Matamba, 1681. MONTECÚCCOLO, Pe. João António Cavazzi de. Descrição histórica dos três reinos do Congo, Matamba e Angola. p. 12. Um ano antes da batalha de Ambuíla, Negreiros tinha solicitado uma devassa sobre Luis Lopes de Siqueira, talvez como forma de ameaçar ou chantagear, para garantir que seus objetivos fossem realizados. Arquivo Histórico Ultramarino-Angola. 25/08/1664. CU, CX-08, D-927. Sobre as guerras na África Centro Ocidental, e principalmente a batalha de Ambuíla, ocorrida em outubro de 1665 ver: THORNTON, John. Warfare in Atlantic Africa, 1500-1800. UCL Press. Londres: 1999.
} 
Ao passarem pelos rios Dande e Lumanha, os batedores do exército conguês se depararam com as tropas lusitanas, o que fez com que D. Antonio recuasse e esperasse mais tropas para a investida. De acordo com fontes portuguesas, que podem ter supervalorizado os números do inimigo, a companhia liderada pelo próprio D. Antonio, Mani Mulanza, tinha aproximadamente "100.000 soldados", criando um grande cerco na batalha. As fontes portuguesas também indicam que as tropas lusitanas em formação de quadrado resistiram a três investidas dos conguêses, até que o próprio D. Antonio liderou a quarta investida, pedindo que capturassem o capitão-mor Luis Lopes de Siqueira ainda vivo, pois ele próprio desejava degolálo. O soberano do Congo acabou levando um tiro de mosquete, sendo capturado e degolado, sua cabeça foi exposta por Siqueira, causando desordem e debandada nas tropas conguêsas, sendo parte delas perseguida pelas tropas lusitanas, muitas lideranças conguêsas foram capturadas e degoladas, já outros foram escravizados ${ }^{46}$. Após a batalha André Vidal ordenou a perseguição ao dembos vassalos do Congo, como Manimotemo Aguingengo, e os sobados do Naboancongo, em uma campanha na qual as tropas lusitanas degolaram as lideranças e escravizaram grande parte da população dessas regiões ${ }^{47}$. Nesse sentido, podemos analisar que, apesar das justificativas que estavam relacionadas às questões religiosas e à busca das minas de cobre ou ouro, o principal resultado das campanhas foi aumentar os números de escravizados para Pernambuco, que era do interesse direto de Negreiros.

Sobre a batalha de Ambuíla, as fontes portuguesas sugerem fatores sobrenaturais para sua vitória, quando não, enaltecem o "heró́smo" dos seus capitães e desprezam a participação dos agrupamentos militares fornecidos pelos sobados aliados, que fizeram toda a diferença no campo de batalha, mesmo com muitos guerreiros desertando. Apesar de algumas diferenças na

\footnotetext{
${ }^{46}$ Há o relato de um soldado português que esteve na batalha, informando detalhes dos acontecimentos e dos números de soldados participantes. BRÁSIO, Padre Antonio. Monumenta Missionária Africana. 1981. p. 575-581, 582-591. O cronista Cadornega também compartilhou dessas informações sobre a batalha. CADORNEGA, Antonio de Oliveira de. História Geral das Guerras Angolanas. p. 206-213. Entre as lideranças mortas estão: o próprio soberano, D. Antonio, um sobrinho do dele, o "duque" de Bamba, o "duque" de Batta, o "duque" de Sandi, o "duque" de Gorimda, o "marquês" de Pemba, o "marquês" de Enmonso, o "marquês" de Choa, o "marquês" de Sembo, o "marquês" de Sonmelo, o "conde" de Sogongo, "General" D. Alvaro Punha, o senhor de Lungo, o senhor de Quina, o senhor de Anquehe, o senhor de Sembo, o senhor de Telamenameno, o senhor de Dirá, o senhor de Quitete, o senhor de Cibanja, o senhor de Metela, o senhor de Meluda, o senhor de Bango, o senhor de Pandi, o senhor de Lula. Essa relação mostra a força política do Estado do Congo, onde tinha muitos aliados que responderam o chamado do pregão de guerra contra os portugueses. BRÁSIO, Padre Antonio. Monumenta Missionária Africana. 1981. p. 589-590. Prisioneiros que foram para Luanda após a batalha: O "Capelão-mor" Manoel Rois de Medeiros, D. Francisco filho natural do soberano, D. Alvaro sobrinho do soberano, D. Pedro sobrinho do soberano, (estes dois são filhos do irmão do soberano, a quem matou para reinar), D. Thomé, "camareiro mor", e mais outros membros da elite conguêsa e sobas vassalos. BRÁSIO, Padre Antonio. Monumenta Missionária Africana. 1981. p. 591.

${ }^{47}$ Sobre a guerra contra o Congo. Arquivo Histórico Ultramarino-Angola. 13/12/1666. CU, CX-09, D1119.
} 
estratégia militar, como a utilização de cavalos e dos mosquetes a roldete, os chefes da "guerra preta" contribuíram de forma decisiva nas campanhas lusitanas no interior de Angola. Muitos desses chefes, de várias regiões, sentiram-se no direito de um maior reconhecimento pelos seus feitos, solicitando benesses e se incorporando às práticas usuais do mundo Atlântico português ${ }^{48}$.

Negreiros e seus capitães conquistaram muito prestígio, pois a vitória contra um "inimigo" de longa data da Coroa portuguesa foi muito celebrada, foram três dias de festividades em Luanda, além do cortejo com a cabeça embalsamada de D. Antonio, desfilando pelas ruas de Luanda até a igreja de Nossa Senhora de Nazaré, onde foi feito um painel em azulejaria retratando cenas da batalha. A coroa real do Congo foi entregue ao governador geral André Vidal, que a prometeu ao Rei D. Afonso VI. Para isso, pediu ao seu sobrinho Antonio Curado Vidal que estava indo para o Recife, cumprir a promessa e entregar a coroa ao Rei de Portugal. Segundo Antonio Curado, a coroa foi roubada durante a viagem ${ }^{49}$.

Nos últimos meses de governo, Negreiros e a Câmara de Luanda escreveram relatos a respeito dos sucessos militares. Entretanto, indicavam que, apesar da vitória, houve muitas baixas e, dessa forma, solicitavam mais militares, principalmente vindos de Pernambuco. Angola, segundo eles, tinha se tornado um dos pontos mais importantes do ultramar lusitano, e a preservação da influência portuguesa na região poderia beneficiar as atividades econômicas no Brasil $^{50}$. A chegada de mais militares vindos de Pernambuco poderia contribuir para que a Capitania continuasse tendo influência nas ações em Angola, ligadas ao tráfico de escravizados, pois a própria batalha de Ambuíla foi uma demonstração desses interesses, porque muitos

\footnotetext{
48 As solicitações de patentes dos chefes da "guerra preta" podem ser vistas em: Arquivo Histórico Ultramarino-Angola. 17/10/1665. CU, CX-09, D-1015. Sobre as questões sobrenaturais na batalha de Ambuíla ver: MONTECÚCCOLO, Pe. João António Cavazzi de. Descrição histórica dos três reinos do Congo, Matamba e Angola. p. 249-251. CADORNEGA, Antonio de Oliveira de. História Geral das Guerras Angolanas. p. 525-526. Sobre as estratégias lusitanas na batalha de Ambuíla ver: FERREIRA, Roquinaldo. O Brasil e a arte da guerra em Angola. Estudos históricos, Rio de Janeiro, nº39, janeiro-junho de 2007. "Guerra preta" foi o termo utilizado pelos portugueses nas fontes para explicar a participação de guerreiros e lideranças africanas como aliados nos conflitos promovidos pelos lusitanos.

${ }^{49}$ A Coroa não realizou as premiações conforme André Vidal solicitou, o mesmo pediu, no início de 1666, uma gratificação de 400 escudos para seus oficiais, mas a Coroa só autorizou as premiações em janeiro de 1667, e apenas 50 escudos para repartir entre os mais importantes na batalha. Arquivo Histórico Ultramarino-Angola. CU, CX-09, D-1099. André Vidal de Negreiros mandou construir a Igreja de Nossa Senhora de Nazaré assim que chegou a Luanda, como promessa de ter se salvado de um possível naufrágio na sua vinda de Pernambuco. A igreja foi concluída em meados de 1664, e após a batalha de Ambuíla, recebeu a cabeça do soberano D. Antonio, onde foi sepultada. Sobre o desaparecimento da coroa real do Congo ver: Arquivo Histórico Ultramarino-Angola. CU, CX-09, D-1119.

${ }^{50}$ Carta da Câmara de Luanda. Arquivo Histórico Ultramarino-Angola. 07/12/1665. CU, CX-09, D-1021, 1119.
} 
prisioneiros foram direcionados aos agentes de Negreiros, que os transportaram diretamente para Pernambuco ${ }^{51}$.

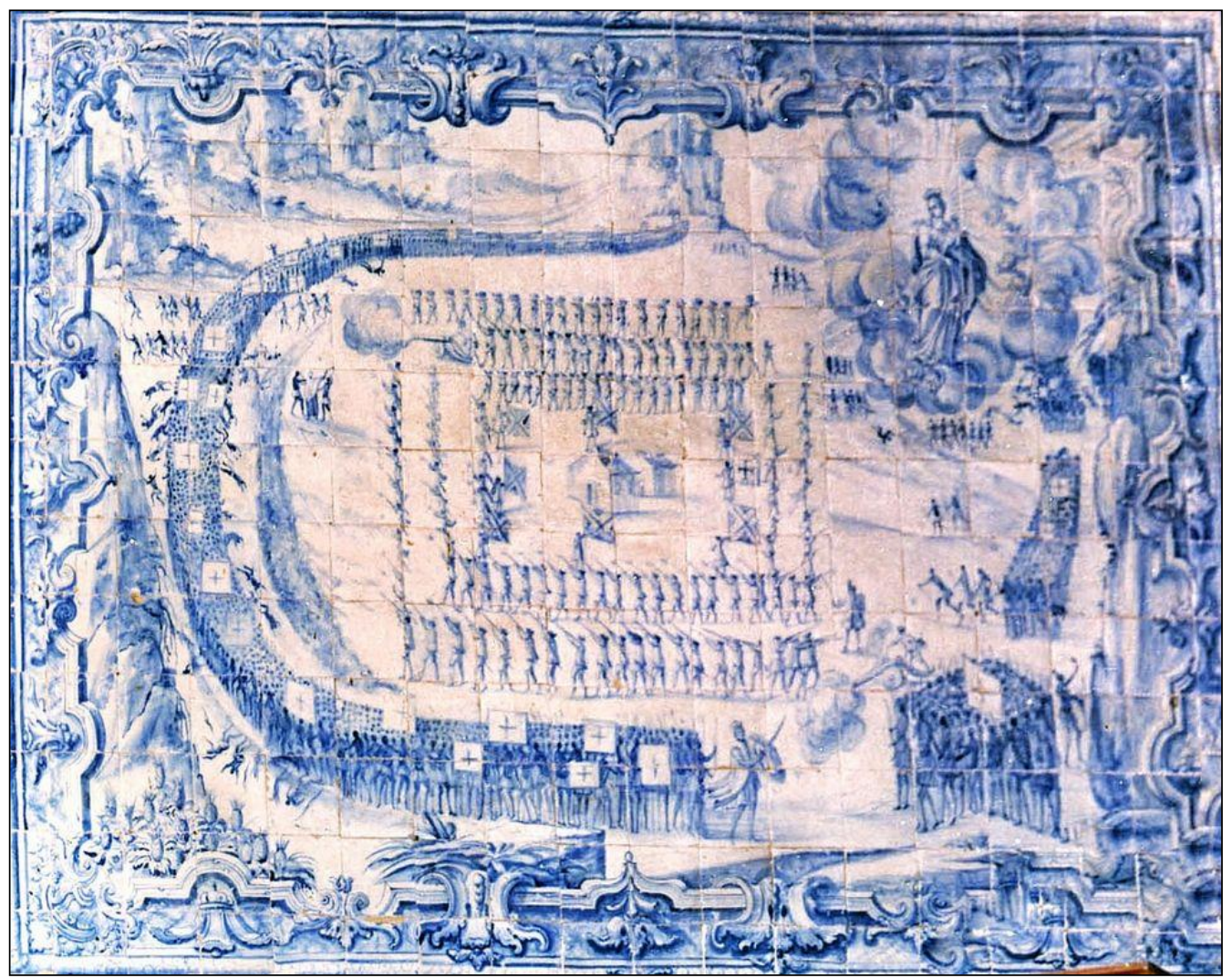

Painéis decorativos de azulejos da Igreja Nossa Senhora de Nazaré, em Luanda, representando a batalha de Ambuíla e a derrota do soberano do Congo, D. Antonio. ${ }^{52}$

Nos dias seguidos à vitória na batalha de Ambuíla, o imaginário com relação às minas de ouro cresceu, porque tanto D. Antonio, quanto vários aliados foram para o confronto com muitos utensílios de ouro, como forma de ostentar suas riquezas. A primeira ação foi exigir do "duque" de Oando um juramento de fidelidade à Coroa. Na cerimônia de undamento, o duque e seus descendentes fizeram várias prerrogativas de vassalagem. Ele foi nomeado pelo governador geral para assumir as terras do Congo, permitindo que mineiros lusitanos pudessem explorar e extrair minérios ${ }^{53}$. Apesar disso, o "duque" não assumiu o cargo, pois foi assassinado.

Juntamente com D. Antonio, morreram os principais candidatos à sucessão do Estado do Congo, abrindo-se então um complicado processo sucessório que fortaleceu a posição da

\footnotetext{
${ }^{51}$ Carta sobre os alimentos destinados aos prisioneiros que tinham destino ao Brasil. Arquivo Histórico Ultramarino-Angola. 08/01/1666. CU, CX-09, D-1030.

${ }^{52}$ Fonte: Museu Nacional de Angola. Foto: D. Wade. In: OGOT, Bethwell Allan (org.). História Geral da África. Volume V. Brasília: UNESCO. 2010, p. 671.

${ }^{53}$ BRÁSIO, Padre Antonio. Monumenta Missionária Africana. Série 1, Volume 13. Lisboa: Academia Portuguesa da História, 1982, p. 3-5.
} 
província do Sonho. Depois da batalha, São Salvador foi palco de várias fugas de nobres para outras províncias, que se tornaram mais autônomas e passaram a escolher seus soberanos, independentemente de em poder central, pelo qual a disputa era constante ${ }^{54}$. A descentralização política e a guerra civil na região do Congo foram relatadas pelo governador de Angola, Francisco de Távora, em 1670, que tentou intervir algumas vezes, sobretudo, em apoiar uma reestruturação do poder central do Congo com relação a suas províncias, principalmente o Sonho, o que não foi autorizado pela Coroa $^{55}$.

Segundo Toby Green, a descentralização do Estado do Congo não se deve exclusivamente às perdas na batalha de Ambuíla, e sim a toda uma construção nas relações de poder a partir do contato com os europeus, pois a globalização de alimentos, ideias e estruturas militares contribuíram com seu eventual declínio. A violência e o comércio de pessoas escravizadas para a expansão do Estado fizeram crescer o ressentimento dos súditos e Estados vizinhos, provocando uma série de revoltas que desestabilizaram o poder central, tornando a região mais aberta e dependente das forças externas. Um grande exemplo foram as importações dos artigos de luxo para os membros do grupo dominante na capital Mbanza Congo, situação que gerava mais desiquilíbrios econômicos e sociais ${ }^{56}$.

Sobre as minas, apesar da expectativa portuguesa, apenas jazidas de cobre foram encontradas ${ }^{57}$. Mesmo com a exploração e o aumento da matéria prima, a substituição dos panos libongos pela moeda de cobre demorou a acontecer. Os sucessores de Negreiros no governo geral de Angola, em parceria com a Câmara de Luanda, continuaram solicitando a mudança e explicando as dificuldades enfrentadas pela desvalorização dos panos. Apenas em 1680 foi decretada por D.Pedro II a aplicação das moedas de cobre, e que se fizesse extinguir os libongos, e, mesmo assim, as moedas só começaram a circular em Luanda em 1694. A circulação da nova moeda não deu muito certo, pois ela só circulava em Luanda e ainda a cunhagem foi feita de forma exagerada, causando desvalorização. Começaram a surgir protestos, principalmente entre os soldados que recebiam o soldo em moedas. A solução projetada pela Câmara de Luanda foi de

\footnotetext{
${ }^{54}$ Sobre o conflito com o duque do Sonho. Arquivo Histórico Ultramarino-Angola. 08/07/1670. CU, CX10, D-1223. Para saber mais sobre o a política da região do Congo após a batalha de Ambuíla ver: THORNTON, John K. The Kingdom of Kongo: civil war and transition (1641-1718). Madison: The University of Winconsin Press, 1983. O Estado só voltou a centralização de poder em 1711.

${ }^{55}$ BRÁSIO, Padre Antonio. Monumenta Missionária Africana. 1982. p. 168-169.

${ }^{56}$ GREEN, Toby. A fistful of shells: West Africa from the rise of the slave trade to the age of Revolution. p. 189.

${ }^{57}$ Em 26 de janeiro de 1666, o Rei de Portugal escreveu aos Cônegos do Cabido do Congo, para que os mesmos colaborassem nos descobrimentos das minas de ouro. BRÁSIO, Padre Antonio. Monumenta Missionária Africana. 1982. p. 7.
} 
diminuir a cunhagem e ampliar sua circulação, utilizando as praças do Brasil, o que só ocorreu em 1704, melhorando a situação ${ }^{58}$.

Data de submissão: $17 / 04 / 2021$

Data de aceite: 06/12/2021

\section{Referências}

\section{Arquivo Histórico Ultramarino-Angola}

ALENCASTRO, Luiz Felipe de. O trato dos viventes: Formação do Brasil no Atlântico Sul. São Paulo: Companhia das letras, 2000.

BLUTEAU, Pe. Raphael. Vocabulário português e latino. Coimbra: Collegio das Artes da Companhia de Jesus, 1712.

BOXER, Charles. Salvador de Sá: e a luta pelo Brasil e Angola, 1602-1686. São Paulo: Companhia editora Nacional, 1973.

BRÁSIO, Padre Antonio. Monumenta Missionária Africana. Série 1, Volumes 10, 11 , 12, 13. Lisboa: Agência Geral do Ultramar, 1965, 1971, 1981, 1982.

CADORNEGA, Antonio de Oliveira de. História Geral das Guerras Angolanas. 2 vol.. Lisboa: Agência-geral do Ultramar, 1940.

GREEN, Toby. A fistful of shells: West Africa from the rise of the slave trade to the age of Revolution. Chicago: The University of Chicago Press, 2019.

MONTECÚCCOLO, Pe. João António Cavazzi de. Descrição histórica dos três reinos do Congo, Matamba e Angola. Volume 2. Lisboa: Junta de Investigações do Ultramar, 1965.

HEINTZE, Beatrix. Angola nos séculos XVI e XVII: estudos sobre fontes, métodos e história. Luanda: Ed.Kilombelombe, 2007.

PARREIRA, Adriano. Economia e sociedade em Angola na época da Rainha Jinga (século XVII). Lisboa: Editorial Estampa, 1989.

\footnotetext{
${ }^{58}$ Sobre as várias solicitações a respeito das moedas de cobre após o governo de André Vidal ver: BRÁSIO, Padre Antonio. Monumenta Missionária Africana. 1982. p. 34, 220-223, 224-225, 406, 412-413, 496-501, 514. Sobre os problemas enfrentados quando da aplicação da moeda em Luanda e as soluções dos problemas ver: CADORNEGA, Antonio de Oliveira de. História Geral das Guerras Angolanas 1940, p. 535-540.
} 